\title{
Second Australian conference on sexually transmissible diseases
}

\author{
Report on the second national conference on sexually transmissible diseases held in Perth, Western Australia, \\ on 16-18 August 1985
}

The second Australian conference on sexually transmissible diseases (STDs) was held in Perth, Western Australia, from 16 to 18 August 1985 . There were 250 registrations from Australia, New Zealand, South East Asia, Canada, the United States of America, and Egypt. (The first conference had been held in Western Australia in 1978 and reported on by Dr R S Morton. ${ }^{1}$ )

The conference was opened on the evening of Friday, 16 August by the Minister of Health, the Hon B J Hodge. He welcomed all registrands and gave a short dissertation outlining the control of STD in Western Australia and the role of the government

The keynote speaker, Dr Malcolm Coppleson, president of the International Society of Colposcopy and Cervical Pathology, reviewed STDs from Biblical, Greek, and Roman times through the centuries, culminating in the present molecular biological applications. Particular reference was made to the consequences of STDs and their implications to the individual and the community.

On the 17 August the conference was held in two venues. It started with reports from the venereologists of New South Wales, Victoria, South Australia, the Australian Capital Territory, and New Zealand outlining local services for the control of STD and current problems.

There followed a report from each of the regions of Western Australia concerning their efforts at STD control. Dr R Spargo from the Kimberley region outlined problems of blood borne diseases and their possible spread in local communities assisted by specific ethnic practices of blood exchange.

Address for reprints: Dr M M Gollow, Communicable Diseases Control Branch, Health Department of Western Australia, 69 Moore Street, Perth, Western Australia 6000, Australia

Accepted for publication 14 November 1985
He postulated the possibility of the spread by these means of the virus that causes the acquired immune deficiency syndrome (AIDS). Miss H Furniss outlined the role of community nurses in contact tracing, diagnosis, and treatment in the Central Region. Dr A Penman outlined the advantage of computerisation in the control of STD. Dr C Naden presented a paper on the role of the community medical officer in the Eastern Goldfields, an enormous region that in parts can only be covered by the Royal Flying Doctor Service.

The session entitled sexually transmissible disasters started with a brief review by $\operatorname{Dr} R$ Henderson of endemic non-venereal syphilis as diagnosed in Western Australia, which was followed by a round up of research in AIDS by Professor R Dawkins.

A discussion paper on the in house gynaecological referral units at the STD clinics, where services include colposcopy, was given by Dr L Farrell. She emphasised the high incidence of abnormal cervical cytology smears and human papillomavirus infection. The final participant in this session, Mr A Hookham from New Zealand, compared cultures and the newer monoconal antibody and enyzme tests for chlamydiae.

During the lunch break, Dr J McCloskey, a trainee venereologist and amateur photographer, presented a magnificent series of views of Western Australia with a commentary and amusing children's stories of the adventures of a teddy bear and his comrades in the Pinnacles desert of Western Australia. The appreciation of the audience for this light interlude was self evident.

The after lunch session started with Dr K Sesnan, senior venereologist, who presented a review of the changing pattern of gonorrhoea with particular reference to the production of a vaccine. This was followed by Dr W Reed of the Perth University department of medicine discussing hepatitis $B$ and present and future vaccines.
Dr $\mathbf{N}$ Brown, venereologist, discussed herpes hysteria and hopes for vaccine production. This was followed by a laboratory report from Dr G Harnett on adenoviruses, eyes, and genitals, which reviewed the association between adenoviruses, nonspecific genital infection, and abnormal cytology.

The penultimate session contained a discussion by Dr M Ross from the University of South Australia on the psychological correlates of promiscuity, with a three country review of homosexuality.

The epidemiology of STD in Western Australia during the past decade was presented by Dr D'Arcy Holman. This essentially showed that despite the sexual revolution, no vast change in the rate of notifiable STDs had occurred.

Mr Stewart Gibb, chief pharmacist of the Royal Perth Hospital, presented a paper on the pharmacology and therapeutics associated with STDs. The final session was by Mrs B Proud, director of information services, who showed how to obtain information concerning STD and how computers could be used to collect and disseminate information quickly throughout the world.

At the alternative venue, the first session of the day was delivered by three nurses and a contact tracer. Sister $\mathrm{C}$ Graham outlined the role of the STD nurse in the clinic; $\mathrm{Mr} \mathrm{T}$ Marshall sketched in the enormous problems of STD control by community nurses in the Kimberley region; and Sister T Aylward detailed the problems of STD education and contact tracing in the ethnic minorities including those that did not speak English. The session concluded with a dissertation on contact tracing by Mrs J Wright, who outlined the educational and counselling role of the health officer in an STD clinic.

The second session outlined one of the most important problems in medicine, namely the bioethical issues in health, in which Mrs J Anstead discussed informed 
consent and the Rev C Honey presented a paper on paternalism. This provoked lively discussion.

The final session at the alternative venue was one on the media and the message of public health, with Dr C Watson of health promotion outlining the varieties of methods available. He was followed by Mr P Frizzell of the Education Department of Western Australia, who presented an outline of the syllabus to be included in all schools in Western Australia in 1986 to extend health education from kindergarten to year 10 . The STD component was to be in years 8,9 and 10 , with the major thrust aimed at the 15 year olds in year 10 .

Dr Susan Robertson of the youth health services outlined the STD problems of teenagers. Mr C O'Doherty, a senior health education officer, spoke about community motivation in dealing with communicable diseases.

The final session of the day was presented by Dr M M Gollow, consultant venereologist of the Communicable Diseases Control Branch, Health Department of Western Australia, on STD control in Western Australia. He emphasised that what had been presented at both venues during the day was the control of STD and that, thanks to the efforts of all the participants in the conference, Western Australia, which covered an area of more than one million square miles and had a population of 1.4 million, was one of the few places in the world where some degree of control of STD had ever been achieved.

On Sunday 18 August the conference continued at the King Edward Memorial Hospital for Women. The morning was devoted to cervical intraepithelial neoplasia (CIN). The first session was a paper by $\mathrm{Dr} C$ D Holman on the changing epidemiological patterns of CIN. Dr M Coppleson followed with a dissertation on the various theories of cervical oncogenesis, with particular emphasis on viral intiators and promoters, histones, and other chemical mediators. Dr Ellis Pixley discussed the relationship between $\mathrm{CIN}$ and the papillomavirus, and described colposcopic diagnosis and the use of laser beam extirpation for treatment.

Dr J Kulski detailed his work on nuclear probing and DNA recombination technology in relation to the human papillomavirus in STD clinic patients in Western Australia. He outline the filter in situ hybridisation (FISH) technique with reference to collection of specimens and to its possible use as a diagnostic procedure.

Dr M Bucens followed with a discussion of both DNA and RNA viruses associated with malignancy known to date. The last paper of the conference was given by Professor $\mathrm{C}$
Michael, who presented a clinician's overview of carcinoma of the cervix emphasising the importance of meticulous management of patients with this condition.

The conference was closed by Dr David Bradford, president of the National Venereology Council of Australia, who thanked all those participating in the conference for their excellent papers and thanked the attenders for their interest and discussion. He commended the excellence of the control of STD in Western Australia, and in particular its undergraduate and postgraduate health care professional teaching programme. He thanked Dr M M Gollow, the convenor of the conference, for its superb organisation, and offered his appreciation of the teamwork so ably displayed, which allows Western Australia to be among the world leaders in the control of STD.

I thank Dr J C McNulty, Executive Director of the Public Health and Scientific Support Services, Health Department of Western Australia, for his permission to print this report, Mrs Joy LeCram for her secretarial services, and Dr N T Brown for reading the manuscript.

M M Gollow

\section{Reference}

Morton RS. Australian conference on STD. British Journal of Venereal Diseases 1979;55:304. 